\title{
Combinatorial Signal Processing in an Insect
}

\author{
Bretta Speck,* Sara Seidita, Samuel Belo, Samuel Johnson, Caley Conley, Camille Desjonquères, \\ and Rafael L. Rodríguez
}

Behavioral and Molecular Ecology Group, Department of Biological Sciences, University of Wisconsin-Milwaukee, Milwaukee, Wisconsin 53211

Submitted October 25, 2019; Accepted May 21, 2020; Electronically published September 8, 2020

Dryad data: https://doi.org/10.5061/dryad.r4xgxd28v.

\begin{abstract}
Human language is combinatorial: phonemes are grouped into syllables, syllables are grouped into words, and so on. The capacity for combinatorial processing is present, in different degrees, in some mammals and birds. We used vibrational insects, Enchenopa treehoppers, to test the hypothesis of basic combinatorial processing against two competing hypotheses: beginning rule (where the early signal portions play a stronger role in acceptability) and no ordering rule (where the order of signal elements plays no role in signal acceptability). Enchenopa males use plant-borne vibrational signals that consist of a whine followed by pulses. We tested the above hypotheses with vibrational playback experiments in which we presented Enchenopa females with stimuli varying in signal element combinations. We monitored female responses to these playbacks with laser vibrometry. We found strong support for combinatorial processing in Enchenopa: in brief, females preferred natural-combination signals regardless of the beginning element and discriminated against reverse-order signals or individual elements. Finding support for the combinatorial rule hypothesis in insects suggests that this capability represents a common solution to the problems presented by complex communication.
\end{abstract}

Keywords: communication, mate choice, signal processing, phonology, syntax, vibrational signaling.

Many aspects of human communication and cognition are built on the basis of mental processing that gives rise to combinatorial and hierarchical structure. In language, this capacity groups sound phonemes into syllables, syllables into words, words into phrases, and so on - and it also creates structure in music, mathematics, and thinking (Pinker 1994; Hauser and Chomsky 2002; Pinker and Jackendoff 2005; Fitch 2010; Corballis 2011; Fitch and Martins 2014).

Combinatorial processing is hypothesized to have originated prior to modern humans and to be present, in different degrees, in other lineages (Fitch 2010). A key distinction is whether processing is only combinatorial or whether it is

* Corresponding author; email: blspeck@uwm.edu.

ORCIDs: Speck, https://orcid.org/0000-0002-3939-5332; Johnson, https:// orcid.org/0000-0002-6201-8914; Conley, https://orcid.org/0000-0002-3351-3609; Desjonquères, https://orcid.org/0000-0002-6150-3264.

Am. Nat. 2020. Vol. 196, pp. 406-413. (C) 2020 by The University of Chicago. 0003-0147/2020/19604-59572\$15.00. All rights reserved.

DOI: $10.1086 / 710527$ also hierarchical and recursive. Basic combinatorial processing involves rules regarding the specific combinations (or orderings) of discrete signal elements that are acceptable to receivers. In human language, for instance, processing at this level combines sound phonemes to form words; for example, in English the sounds $/ \mathrm{k} /, / æ /$, and $/ \mathrm{t} /$ are combined to form the word "cat" (Bowling and Fitch 2015). Some authors refer to such processing as "phonology" (Fitch 2010:94) or "finite state grammar" (Zuberbühler 2019:2). Examples of this basic combinatorial processing can be found in some primates, bats, hyraxes, and birds (table 1). Combinatorial processing may go beyond the abovementioned basic level and generate hierarchical structuring by recursive embedding of combinations of signal elements (Pinker 1994; Hauser and Chomsky 2002; Pinker and Jackendoff 2005; Fitch 2010; Fitch and Martins 2014). In human language, processing at this level combines words to form phrases (e.g., "cats purr") that can be further combined with other phrases and embedded in sentences and more complex structures (Bowling and Fitch 2015). Some authors refer to this type of processing as "syntax" (Fitch 2010:100) or "phrase structure grammar” (Zuberbühler 2019:2). Examples of this more complex combinatorial-hierarchical processing can be found in some whales and birds (table 1; Bergman et al. 2019; Suzuki et al. 2019).

Similarities in the capacity for combinatorial processing across different species may represent common descent or convergent solutions to the problems that animals face in complex environments and complex communication systems (Fitch 2010). Consequently, understanding the evolution of combinatorial processing in animals, as well as the course it followed in our lineage, requires exploring the diversity and taxonomic distribution of combinatorial processing capabilities among animals.

Here we report basic combinatorial processing in the communication system of an insect, a member of the Enchenopa binotata species complex of treehoppers (Hemiptera: Membracidae). Enchenopa treehoppers are phloemfeeding insects that communicate with plant-borne vibrational signals (Cocroft and Rodríguez 2005; Cocroft et al. 2008). Males produce advertisement signals consisting of 
Table 1: Examples of basic and hierarchical combinatorial processing in animals

\begin{tabular}{|c|c|c|}
\hline Species & Method of testing & Reference \\
\hline \multicolumn{3}{|l|}{ Basic combinatorial processing: } \\
\hline \multicolumn{3}{|l|}{ Birds: } \\
\hline Black-capped chickadee (Parus atricapillus) & Structure of naturally occurring calls & Hailman et al. 1987 \\
\hline Swamp sparrow (Melospiza georgiana) & Ability to learn test sequences & Marler and Peters 1988 \\
\hline Yellow-naped amazons (Amazona auropalliata) & Structure of naturally occurring calls & Dahlin and Wright 2009 \\
\hline Java sparrows (Lonchura oryzivora) & $\begin{array}{l}\text { Structure of spontaneously occurring calls } \\
\text { in tutored and nontutored males }\end{array}$ & Soma and Mori 2015 \\
\hline \multicolumn{3}{|l|}{ Chestnut-crowned babbler (Pomatostomus } \\
\hline ruficeps) & Habituation & Engesser et al. 2019 \\
\hline Great tit (Parus major) & Innate response to playbacks & Dutour et al. 2019 \\
\hline Coal tit (Periparus ater) & Innate response to playbacks & Dutour et al. 2019 \\
\hline Common chaffinch (Fringilla coelebs) & Innate response to playbacks & Dutour et al. 2019 \\
\hline \multicolumn{3}{|l|}{ Primates: } \\
\hline Wedge-capped capuchins (Cebus olivaceus) & Structure of naturally occurring calls & Robinson 1984 \\
\hline Cotton-top tamarins (Saguinus Oedipus) & Habituation & Fitch and Hauser 2004 \\
\hline Chimpanzee (Pan troglodytes) & Structure of naturally occurring calls & Crockford and Boesch 2005 \\
\hline Putty-nosed monkey (Cercopithecus nictitans) & Innate response to playbacks & Arnold and Zuberbühler 2008 \\
\hline $\begin{array}{l}\text { Campbell's monkeys (Cercopithecus campbelli } \\
\text { campbelli) }\end{array}$ & $\begin{array}{l}\text { Structure of naturally occurring calls } \\
\text { and innate response to playbacks }\end{array}$ & Ouattara et al. 2009 \\
\hline Red-capped mangabeys (Cercocebus torquatus) & $\begin{array}{l}\text { Structure of naturally occurring calls } \\
\text { in captivity }\end{array}$ & Bouchet et al. 2010 \\
\hline Titi monkey (Callicebus nigrifrons) & Structure of naturally occurring calls & Cäsar et al. 2013 \\
\hline Western gorilla (Gorilla gorilla) & Structure of naturally occurring calls & Hedwig et al. 2015 \\
\hline Mountain gorilla (Gorilla beringei beringei) & Structure of naturally occurring calls & Hedwig et al. 2015 \\
\hline Geladas (Theropithecus gelada) & Innate response to playbacks & Gustison and Bergman 2016 \\
\hline Bonobos (Pan paniscus) & Structure of naturally occurring calls & Schamberg et al. 2016 \\
\hline Rhesus macaques (Macaca Mulatta) & Ability to learn test sequences & Heimbauer et al. 2018 \\
\hline \multicolumn{3}{|l|}{ Other mammals: } \\
\hline Mustached bat (Pteronotus parnellii parnellii) & Structure of naturally occurring calls & Kanwal et al. 1994 \\
\hline Rock hyrax (Procavia capensis) & Innate response to playbacks & Kershenbaum et al. 2012 \\
\hline \multicolumn{3}{|l|}{ Hierarchical combinatorial processing: } \\
\hline \multicolumn{3}{|l|}{ Birds: } \\
\hline Song sparrow (Melospiza melodia) & Ability to learn test sequences & Marler and Peters 1988 \\
\hline European starlings (Sturnus vulgaris) & Habituation & Gentner et al. 2006 \\
\hline \multicolumn{3}{|l|}{ Yellow-naped Amazons (Amazona } \\
\hline auropalliata) & Structure of naturally occurring calls & Dahlin and Wright 2009 \\
\hline Cassin’s Vireos (Vireo cassinii) & Innate response to playbacks & Hedley et al. 2017 \\
\hline \multicolumn{3}{|l|}{ Other mammals: } \\
\hline Humpback whales (Megaptera novaeangliae) & Structure of naturally occurring calls & Allen et al. 2019 \\
\hline
\end{tabular}

two elements: a whine (W) followed by a series of pulses (P; Cocroft et al. 2010; fig. 1). This WP signal structure is highly conserved in the E. binotata complex, while other signal features (especially dominant frequency) are strongly species specific and covary with divergent female preferences (Rodríguez et al. 2006; Cocroft et al. 2008, 2010). This conservation of basic signal structure against the background of strong divergence in other traits suggests either strong stabilizing selection on signal structure or strong signal-production constraints. While PW variants are observed only rarely in the E. binotata complex (R.B. Cocroft, personal communication), reversals in signal structure are common across species in treehoppers and other vibrational insects (Cocroft 2003; Percy et al. 2006, 2008). This observation argues against production constraints, and we therefore focus here on testing for a female combinatorial processing rule for signal structure in Enchenopa treehoppers.

We tested the combinatorial rule hypothesis in terms of the Enchenopa communication system and the twoelement (WP) structure of male advertisement signals (predictions $\mathrm{i}$-iii in table 2). We tested this hypothesis against two competing alternatives. First, signal processing might not be truly combinatorial; instead, earlier elements 

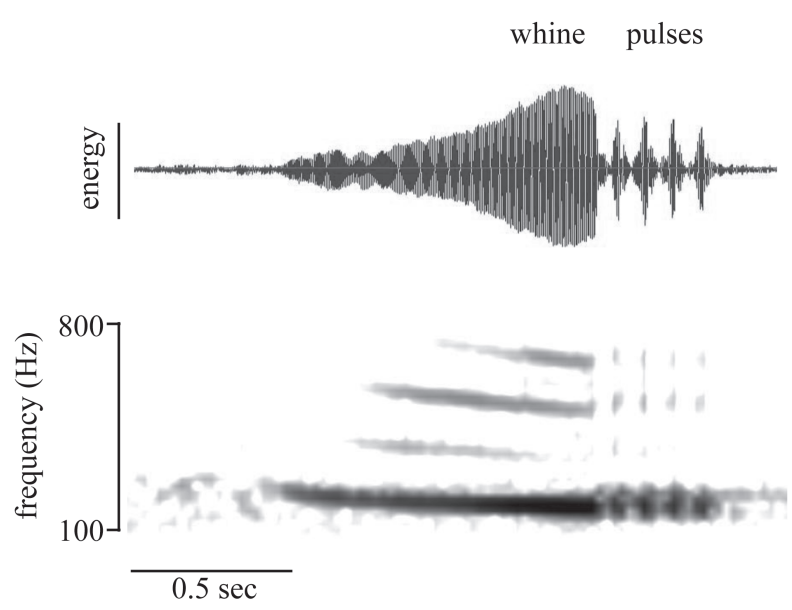

Figure 1: The two-element male advertisement signal of Enchenopa treehoppers, shown as an oscillogram (top) and spectrogram (bottom).

may simply have stronger effects on signal acceptability than later signal elements. There is evidence in support of this hypothesis from studies in some insects and frogs, which have referred to the "temporal-order effect" hypothesis (Gerhardt et al. 2007; Reichert et al. 2017). We use the term "beginning rule" to emphasize that this hypothesis focuses on the strength of the effect of the beginning of signals rather than on the combination of elements per se (prediction iv in table 2). The second competing hypothesis is the null or "no ordering rule" hypothesis, whereby many possible arrangements of signal elements are acceptable (prediction $\mathrm{v}$ in table 2). There is evidence in support of this hypothesis from studies in some frog species (Wilczynski et al. 1999; Oliva et al. 2018).

We also contrasted the response to the naturalcombination stimulus (WP) against the single element stimuli (W and P). These tests do not directly address the logic of the hypotheses, but inform us of the relative importance of the presence of each signal element per se.

We tested the predictions described above (table 2) with a vibrational playback experiment in which we presented Enchenopa females with synthetic stimuli varying in signal element composition to assess their acceptability. The combinatorial processing literature includes a very broad range of methods, from analysis of the structure of naturally occurring signals to experiments requiring sophisticated learning abilities in the animals to test the hypotheses (table 1). Our experiment tests for differences in female responsiveness to stimuli varying in signal element combinations. It makes no assumptions about whether those differences are innate or acquired (although the former seems likely). The tests involve potential effects from preceding signal elements on subsequent signal elements (combinatorial rule and beginning rule hypotheses). We therefore presented each female with only one stimulus. Our experiment thus assessed variation in the responses of females across stimuli to test for population-level rules regarding signal element combinations.

\section{Methods}

We worked with one of the two Enchenopa binotata species that live on Viburnum lentago (Adoxaceae) bushes and trees in Wisconsin. Most of the species in the complex have

Table 2: Hypotheses that analyze processing of signal element combinations in Enchenopa treehoppers as well as their predictions

\begin{tabular}{|c|c|c|}
\hline Hypothesis & Prediction & Summary \\
\hline \multirow[t]{3}{*}{ Combinatorial rule } & $\begin{array}{l}\text { Prediction i: females should prefer the natural-combination stimulus over a } \\
\text { reverse-order stimulus }\end{array}$ & $\mathrm{WP}>\mathrm{PW}$ \\
\hline & $\begin{array}{l}\text { Prediction ii: females should make no distinction between the natural-combination } \\
\text { stimulus and a stimulus beginning with the wrong element but containing the } \\
\text { natural combination stimulus }\end{array}$ & $\mathrm{WP}=\mathrm{PWP}$ \\
\hline & $\begin{array}{l}\text { Prediction iii: females should prefer a stimulus beginning with the wrong element } \\
\text { but containing the natural combination stimulus over a reverse-order stimulus }\end{array}$ & $\mathrm{PWP}>\mathrm{PW}$ \\
\hline Beginning rule & $\begin{array}{l}\text { Prediction iv: females should prefer stimuli with the natural-beginning element over } \\
\text { stimuli beginning with the wrong element }\end{array}$ & $\begin{aligned} \mathrm{WP} & >\mathrm{PW} \\
\mathrm{WP} & >\mathrm{PWP} \\
\mathrm{W} & >\mathrm{PW} \\
\mathrm{W} & >\mathrm{PWP}\end{aligned}$ \\
\hline No ordering rule & $\begin{array}{l}\text { Prediction v: females should make no distinction between stimuli with different } \\
\text { signal element combinations }\end{array}$ & $\mathrm{WP}=\mathrm{PW}=\mathrm{PWP}$ \\
\hline
\end{tabular}

Note: We did not contrast the response to whine (W) and pulse (P) stimuli because this comparison might depend not only on the beginning of the P stimulus but also on it being insufficient on its own. 
not yet been formally described (Hamilton and Cocroft 2009), but they can be distinguished by their host plant, nymph coloration, and the dominant frequency of adult male signals (Wood 1980, 1993; Rodríguez et al. 2004; Cocroft et al. 2008, 2010). We used the species that has male signals with a dominant frequency of $185 \mathrm{~Hz}$.

We conducted the study over the summers of 2016 and 2017. In 2016, we collected the treehoppers in June as late instar nymphs at the University of Wisconsin-Milwaukee's (UWM's) Downer Woods and then reared them to maturity on potted $V$. lentago plants in the UWM greenhouse. In 2017, we used nymphs reared from eggs that we hatched in the greenhouse ahead of the summer season.

We separated adult females from males 1-3 days after their final molt. Separation was essential to prevent the females from mating, thus keeping them sexually receptive and responsive to playbacks. We began our trials when the females reached sexual maturity, 4 weeks after the adult molt.

We created vibrational playback stimuli on an iMac computer using Matlab version 7.5.0.338 (Mathworks, Natick, MA; http://www.mathworks.com). The playback stimuli varied in the combination of signal elements presented to females as follows: stimuli had either the natural whine-pulse (WP) signal element combination, the reverse pulse-whine (PW) element combination, a pulse-whinepulse (PWP) element combination, a single whine (W) element, or a single pulse (P) element. We set all other stimulus features to the population mean $(185 \mathrm{~Hz}$ dominant frequency, $950 \mathrm{~ms}$ whine length, 3 pulses, $38 \mathrm{~ms}$ pulse length, and $21 \mathrm{~Hz}$ pulse rate; R. L. Rodríguez unpublished data), except that we used only one signal per stimulus rather than the typical signal bout structure (Cocroft et al. 2010) to avoid possible confounding effects of preceding stimuli on subsequent stimuli (a possibility under the combinatorial and beginning rule hypotheses).

We presented each female with a single, randomly assigned playback stimulus (i.e., we tested each female only once). Thus, responses to each stimulus by each female are fully independent of each other. Furthermore, this was necessary in our study because of the potential for confounding effect of preceding stimuli on subsequent stimuli (see the rationale described above).

To present females with a playback stimulus, we placed each female singly on a small potted $V$. lentago plant and allowed her to roam and settle (for a minimum of $30 \mathrm{~s}$ and a maximum of $10 \mathrm{~min}$ ) before presenting her with a single, randomly selected stimulus. Enchenopa females that find a male's signal attractive respond with their own singleelement signals, establishing a duet that lasts until mating begins (Rodríguez and Cocroft 2006; Cocroft et al. 2008; Rodríguez et al. 2012). Our assay of stimulus acceptability took advantage of this aspect of the Enchenopa communication system: we noted whether a female produced a du- etting signal in response to the stimulus. If the female did not respond to the stimulus, we presented her with the playback of a recording of a male signal to confirm that she was sexually receptive and that she did not respond to the experimental stimulus because it was unattractive to her. If she did not respond to the playback of the recorded male, we retested her $1-3$ days later. We tested $n=40 \mathrm{fe}$ males for each of the five stimuli $(n=20$ females per stimulus per year).

We imparted the playback stimuli onto the test plant with a piezo-electric controller and actuator (Thorlabs, Newton, NJ) attached to its stem with wax. We delivered all stimuli at a peak amplitude of $0.15 \mathrm{~mm} / \mathrm{s}$.

We recorded the stimuli and female responses with a laser vibrometer (Polytec PLV-100; Polytec, Auburn, MA). We sent the output of the laser vibrometer through a bandpass filter (40-4000 Hz; Krohn-Hite 3202; KrohnHite, Brockton, MA) and digitized it on an iMac with a sampling rate of $44.1 \mathrm{kHz}$ using the program Audacity (ver. 2.1.2; www.audacityteam.org). After testing, we returned females to the laboratory colony or to the field (Downer Woods).

\section{Statistical Analysis}

We conducted the statistical analysis in two steps. We first tested for variation in the likelihood of female response to the different stimuli. The model had female response $(0$ for no response, 1 for response) as the dependent variable. The error structure was a binomial distribution. The explanatory variables were stimulus (i.e., signal element combination), year, and their interaction. Because of complete separation in the data ( $0 \%$ response for one stimulus; see below), the maximum likelihood estimates of the regression coefficients could not be estimated, as they do not exist (Albert and Anderson 1984). We therefore used a Bayesian generalized linear model with a Cauchy prior (Gelman et al. 2008). We fit the model in R using the function bayesglm of the lme4 package (ver. 1.10-1; Gelman and $\mathrm{Su} 2018$ ). We checked model stability by excluding data points one at a time from the data set and found that all the coefficient estimates were stable. We derived variance inflation factors (Field 2009) with the vif function of the car package (ver. 3.0-3; Fox and Weisberg 2011). We found no collinearity between fixed effects.

The second step of our analysis was to test each of the predictions specifically (table 2). To this end, we used Tuckey post hoc tests to compare the response to each of the relevant stimulus pairs. We obtained these comparisons from a model with only the main terms (stimulus and year), as their interaction was not significant. Data for these analyses have been deposited in the Dryad Digital Repository (https://doi.org/10.5061/dryad.r4xgxd28v; Speck et al. 2020). 


\section{Results}

Enchenopa females varied in their likelihood to respond to the playback stimuli according to signal element combinations (significant stimulus term in table 3; fig. 2). The term for year was also significant, with females tested in 2016 being overall more responsive than those tested in 2017 (table 3; fig. 2). However, the stimulus $\times$ year interaction was not significant (table 3 ), indicating that the patterns of response were similar across years (fig. 2). On the basis of the above overall effect of stimulus signal element combination on female responses, we used post hoc tests to pinpoint the comparisons specified by the hypotheses' predictions (table 2 ).

In support of the combinatorial rule hypothesis, Enchenopa females were significantly more likely to respond to the natural-combination stimulus (WP) than to the reverseorder stimulus (PW; table 4; fig. 2; supporting prediction i). Females were also about as likely to respond to the natural-combination stimulus (WP) as to the stimulus containing the natural combination but beginning with the wrong element (PWP): the difference in response was small and nonsignificant (table 4; fig. 2; supporting prediction ii). Females were also significantly more likely to respond to the natural-combination beginning with the wrong element (PWP) than to the reverse-order stimulus (PW; table 4; fig. 2; supporting prediction iii).

The comparison between the natural-combination stimulus (WP) to the reverse-order stimulus (PW) would also support the beginning rule hypothesis (table 4; fig. 2; prediction iv). However, in opposition to prediction iv, we found the following results: Enchenopa females were not significantly more likely to respond to the natural-combination stimulus (WP) than to the stimulus containing the natural combination but beginning with the wrong element (PWP; table 4; fig. 2), they were not more likely to respond to the single whine element stimulus (W) than to the reverseorder stimulus (PW; table 4; fig. 2), and they were significantly more likely to respond to the natural-combination stimulus

Table 3: Analysis of variation in the likelihood of Enchenopa female response to vibrational playback stimuli varying in element composition

\begin{tabular}{lccc}
\hline Term & df & $z$ & $P$ \\
\hline Stimulus & 4 & $55.74^{*}$ & $\ll .001^{*}$ \\
Year & 1 & $19.85^{*}$ & $.0013^{*}$ \\
Stimulus $\times$ year & 4 & 1.22 & .87 \\
\hline
\end{tabular}

Note: We used a Bayesian generalized linear model with a binomial error distribution to test the effect of the playback treatments, year of testing, and the playback $\times$ year interaction (model explanation in text). The main terms remain nearly identical after removing the nonsignificant interaction (stimulus: $z=54.51, P \ll .0001$; year: $z=18.63, P \ll .0001$ ).

* Significant term.

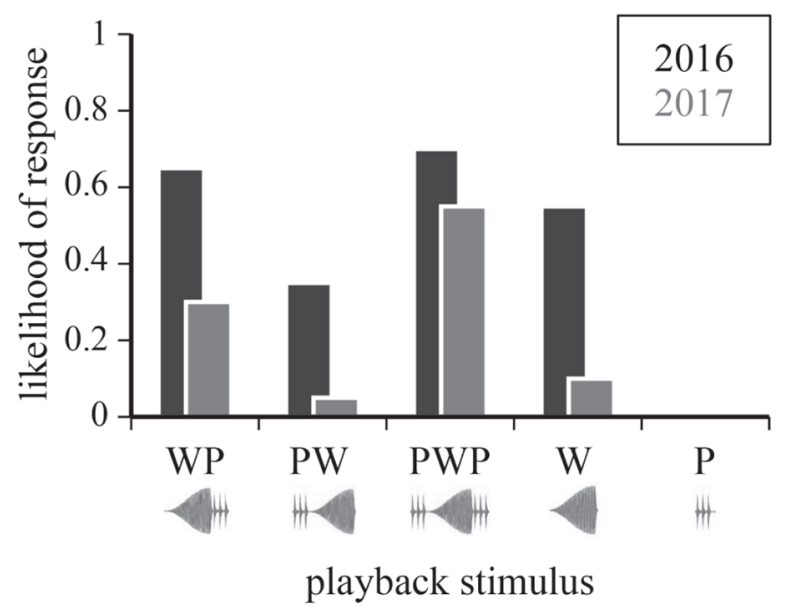

Figure 2: Tests for combinatorial signal processing in Enchenopa treehoppers. We show the likelihood of response to the playback stimuli: the natural-combination stimulus (WP), the reverse-order stimulus (PW), the stimulus beginning with the wrong element but containing the natural combination (PWP), the single whine element stimulus (W), and the single pulse element stimulus (P). Black bars $=2016$ data; gray bars $=2017$ data .

beginning with the wrong element (PWP) than to the single whine element stimulus (W; table 4; fig. 2).

Additionally, the overall significant effect of the stimulus term (table 3 ) and the predominance of significant comparisons supporting the combinatorial rules hypothesis (table 4; fig. 2) reject prediction $\mathrm{v}$ of the null no ordering rules hypothesis. Finally, Enchenopa females tended to be more likely to respond to the natural-combination stimulus (WP) than to either of the single-element stimuli (W or P), but only significantly so against the P stimulus (table 4; fig. 2).

\section{Discussion}

We tested for basic combinatorial signal processing in Enchenopa treehoppers with playback experiments varying signal element structure. We found that Enchenopa females were more likely to respond to the natural-combination stimulus (WP) than to the reverse-combination (PW) stimulus. Interestingly, they were not more likely to respond to the natural-combination stimulus (WP) than to the naturalcombination stimulus with the wrong element tacked in front (PWP), but they were more likely to respond to the latter than to the reverse-combination (PW) stimulus. They also were more likely to respond to the natural-combination stimulus with the wrong beginning element (PWP) than to the single whine element (W) stimulus, but they were not 
Table 4: Comparison of the likelihood of Enchenopa female response according to stimulus pairings that address the predictions of the hypotheses

\begin{tabular}{lcccc}
\hline Stimulus comparison $^{\mathrm{a}}$ & $z$ & $P$ & Predictions supported & Predictions rejected \\
\hline WP-PW & $2.71^{*}$ & $.0497^{*}$ & $\mathrm{i}, \mathrm{iv}$ & $\mathrm{v}$ \\
WP-PWP & -1.44 & .59 & $\mathrm{ii}$ & iv \\
PWP-PW & $3.92^{*}$ & $<.0001^{*}$ & iii & iv, $\mathrm{v}$ \\
W-PW & 1.34 & .65 & & iv \\
W-PWP & $-2.82^{*}$ & $.037^{*}$ & iv, $\mathrm{V}$ \\
WP-W & 1.46 & .58 & \\
WP-P & $4.22^{*}$ & $<.0001^{*}$ & $\mathrm{v}$ \\
W-P & $3.30^{*}$ & $.0078^{*}$ & $\mathrm{v}$ \\
\hline
\end{tabular}

Note: We show the results of the post-hoc tests from the Bayesian generalized linear model that included only the main terms for stimulus and year (see text and table 3). Abbreviations are as in table 2.

a There are two additional comparisons that we do not emphasize because they do not address any specific prediction; reported here for completeness: PW-P: $z=2.34, P=.13$; PWP-P: $z=5.03, P<.001$.

${ }^{*}$ Significant term.

more likely to respond to the single whine element (W) stimulus than to the reverse-order stimulus (PW). These results thus strongly support the combinatorial rule hypothesis and strongly oppose the beginning rule and no ordering rule hypotheses (table 2 ).

A potential confounding factor in these tests is that some stimuli varied not only in element combination but also in length, potentially influencing female responses because of the overall strength of the stimulation provided (e.g., the WP stimulus may have stimulated females more strongly than the single-element stimuli, and the PWP stimulus may have stimulated females more strongly than the WP stimulus or the W stimulus). We consider, however, that this is not an important confounding factor in our results. First, Enchenopa mate preferences for signal length favor intermediate values (with the preferred length varying across species), rather than longer values (Rodríguez et al. 2004, 2006). Thus, a simple response to stronger stimulation in longer stimuli is unlikely to have an influence in our data. Furthermore, in a crucial test (WP vs. PW), the competing stimuli had the same length but varied in acceptability: this pinpoints element combination as the key factor. Additionally, some nonsignificant comparisons involved stimuli of different lengths (WP vs. PWP, W vs. PW, and WP vs. W), with the pattern in one of those being of greater response to the shorter stimulus (W vs. PW; table 4; fig. 2). We therefore conclude that any effect of stimulus length was at best secondary to the effect of signal element combinations.

Variation in female responsiveness over the 2 years of testing may be due to females in the second year being slightly younger than those in the first year (or to additional variables arising from working with field-collected vs. greenhouse-reared treehoppers; e.g., early development effects). Nevertheless, the patterns of signal acceptability that we detect were robust to those differences. We therefore interpret our results in terms of the effect of signal element composition.

Thus, our results support the combinatorial rule hypothesis and reject the competing beginning rule and no ordering rule hypotheses: signal processing in Enchenopa includes rules about the combination of the two elements of male signals. If these rules are conserved across the E. binotata complex, they may explain the highly conserved structure of male advertisement signals in spite of remarkable signal preference codivergence in continuous signal features (especially dominant signal frequency; Rodríguez et al. 2006; Cocroft et al. 2008, 2010). However, structure reversal across different species is widespread in animals that communicate with substrate-borne vibrational signals (e.g., Cocroft 2003; Percy et al. 2006, 2008). This observation suggests that the rules that govern the combinations of signal elements that are acceptable to receivers also diverge frequently.

We might have initially expected combinatorial rules to be categorical, that is, to render signal element combinations either acceptable or completely unacceptable. However, although stimuli with the wrong combinations considerably lowered female responsiveness, only a few stimuli were consistently rejected by a large majority of females (fig. 2). It will therefore be interesting to explore the nature of the relationship between combinatorial rules and preferences for continuous signal traits (such as signal frequency) and the different forms that this relationship may take across different species.

We note that our experiment may not have probed the limit of Enchenopa combinatorial capabilities; it remains to be tested whether they may have more sophisticated hierarchical capabilities. Some insects and spiders have far more elaborate multielement signals than Enchenopa. Some jumping spiders, for instance, have multimodal signals that 
rival the most elaborate displays of vertebrates in complexity (e.g., Girard et al. 2011; Elias et al. 2012). Higher-level combinatorial processing than we have documented here may be involved in such cases.

Shared combinatorial processing capabilities across vertebrates and invertebrates most likely represents convergence, rather than common descent, as the last common ancestor of these groups likely had a simple neural system (Feinberg and Mallatt 2016). Further studies will be required to see how widespread this capability is in invertebrates. We conclude, however, with the suggestion that combinatorial processing may represent a common solution to the problems presented by complex communication in a complex world.

\section{Acknowledgments}

We thank Gerlinde Höbel and Clint Sergi for their helpful discussions and comments on the manuscript. We also thank Paul Engevold for his assistance and greenhouse expertise, Jak Maliszewski for help with insect collection, and the University of Wisconsin-Milwaukee (UWM) Field Station staff for their support. This work was supported by a Research Growth Initiative Grant from UWM to R.L.R. and UWM Support for Undergraduate Research Fellows (SURF) awards to S.S., S.B., S.J., and C.C. All our procedures adhere to the legal requirements of the country in which the work was carried out and all institutional guidelines. We declare we have no competing interests.

\section{Statement of Authorship}

B.S. participated in the design of the study, coordinated and carried out field and lab work, participated in data analysis and in statistical analysis, and drafted the manuscript; S.S. carried out field and lab work and participated in data analysis. S.B. carried out field and lab work and participated in data analysis; S.J. carried out field and lab work and participated in data analysis; C.C. carried out field and laboratory work and participated in data analysis; and C.D. conducted the statistical analysis and helped write the manuscript. R.L.R. conceived, designed, and coordinated the study; carried out statistical analysis; and critically revised the manuscript. All authors gave final approval for publication and agree to be held accountable for the work performed therein.

\section{Data and Code Availability}

Data for these analyses have been deposited in the Dryad Digital Repository (https://doi.org/10.5061/dryad.r4xgxd28v; Speck et al. 2020).

\section{Literature Cited}

Albert, A., and J. A. Anderson. 1984. On the existence of maximum likelihood estimates in logistic regression models. Biometrika 71: $1-10$.

Allen, J. A., E. C. Garland, R. A. Dunlop, and M. J. Noad. 2019. Network analysis reveals underlying syntactic features in a vocally learnt mammalian display, humpback whale song. Proceedings of the Royal Society B 286:20192014.

Arnold, K., and K. Zuberbühler. 2008. Meaningful call combinations in a non-human primate. Current Biology 18:R202-R203.

Bergman, T. J., J. C. Beehner, M. C. Painter, and M. L. Gustison. 2019. The speech-like properties of nonhuman primate vocalizations. Animal Behaviour 151:229-237.

Bouchet, H., A. S. Pellier, C. Blois-Heulin, and A. Lemasson. 2010. Sex differences in the vocal repertoire of adult red-capped mangabeys (Cercocebus torquatus): a multi-level acoustic analysis. American Journal of Primatology 72:360-375.

Bowling, D. L., and W. T. Fitch. 2015. Do animal communication systems have phonemes? Trends in Cognitive Sciences 19:555-557.

Cäsar, C., K. Zuberbühler, R. J. Young, and R. W. Byrne. 2013. Titi monkey call sequences vary with predator location and type. Biology Letters 9:20130535

Cocroft, R. B. 2003. The social environment of an aggregating, antattended treehopper (Hemiptera: Membracidae: Vanduzea arquata). Journal of Insect Behavior 16:79-95.

Cocroft, R. B., and R. L. Rodríguez. 2005. The behavioral ecology of insect vibrational communication. BioScience 55:323-334.

Cocroft, R. B., R. L. Rodríguez, and R. E. Hunt. 2008. Host shifts, the evolution of communication, and speciation in the Enchenopa binotata species complex of treehoppers. Pages 88-100 in K. J. Tilmon, ed. Specialization, speciation and radiation: the evolutionary biology of herbivorous insects. University of California Press, Berkeley.

- 2010. Host shifts and signal divergence: mating signals covary with host use in a complex of specialized plant-feeding insects. Biological Journal of the Linnean Society 99:60-72.

Corballis, M. C. 2011. The recursive mind: the origins of human language, thought, and civilization. Princeton University Press, Princeton, NJ.

Crockford, C., and C. Boesch. 2005. Call combinations in wild chimpanzees. Behaviour 142:397-421.

Dahlin, C. R., and T. F. Wright. 2009. Duets in yellow-naped Amazons: variation in syntax, note composition and phonology at different levels of social organization. Ethology 115:857-871.

Dutour, M., T. Lengagne, and J. Léna. 2019. Syntax manipulation changes perception of mobbing call sequences across passerine species. Ethology 125:635-644.

Elias, D. O., W. P. Maddison, C. Peckmezian, M. B. Girard, and A. C. Mason. 2012. Orchestrating the score: complex multimodal courtship in the Habronattus coecatus group of Habronattus jumping spiders (Araneae: Salticidae). Biological Journal of the Linnean Society 105:522-547.

Engesser, S., J. L. Holub, L. G. O’Neill, A. F. Russell, and S. W. Townsend. 2019. Chestnut-crowned babbler calls are composed of meaningless shared building blocks. Proceedings of the National Academy of Sciences of the USA 116:19579-19584.

Feinberg, T. E., and J. Mallatt. 2016. The ancient origins of consciousness: how the brain created experience. MIT Press, Cambridge, MA.

Field, A. 2009. Discovering statistics using SPSS statistics. Sage, Thousand Oaks, CA. 
Fitch, W. T. 2010. The evolution of language. Cambridge University Press, Cambridge.

Fitch, W. T., and M. D. Hauser. 2004. Computational constraints on syntactic processing in a nonhuman primate. Science 303:377-380.

Fitch, W. T., and M. D. Martins. 2014. Hierarchical processing in music, language, and action: Lashley revisited. Annals of the New York Academy of Sciences 1316:87-104.

Fox, J., and S. Weisberg. 2011. No, an R companion to applied regression. 2nd ed. Sage, Thousand Oaks, CA.

Gelman, A., and Y. Su. 2018. arm: data analysis using regression and multilevel/hierarchical models. https://CRAN.R-project.org/pack age $=$ arm.

Gelman, A., A. Jakulin, M. G. Pittau, and Y. S. Su. 2008. A weakly informative default prior distribution for logistic and other regression models. Annals of Applied Statistics 2:1360-1383.

Gentner, T. Q., K. M. Fenn, D. Margoliash, and H. C. Nusbaum. 2006. Recursive syntactic pattern learning by songbirds. Nature 440:1204-1207.

Gerhardt, H. C., S. C. Humfeld, and V. T. Marshall. 2007. Temporal order and the evolution of complex acoustic signals. Proceedings of the Royal Society B 274:1789-1794.

Girard, M. B., M. M. Kasumovic, and D. O. Elias. 2011. Multimodal courtship in the peacock spider, Maratus volans (O.P. Cambridge, 1874). PLoS ONE 6:e25390.

Gustison, M. L., and T. J. Bergman. 2016. Vocal complexity influences female responses to gelada male calls. Scientific Reports 6:1-9.

Hailman, J. P., M. S. Ficken, and R. W. Ficken. 1987. Constraints on the structure of combinatorial "chick-a-dee" calls. Ethology 75:62-80.

Hamilton, K. G. A., and R. B. Cocroft. 2009. Establishing the identity of existing names in the North American Enchenopa binotata species complex of treehoppers (Hemiptera: Membracidae). Entomological News 120:554-565.

Hauser, M. D., and N. Chomsky. 2002. The faculty of language: what is it, who has it, and how did it evolve? Science 298:1569-1579.

Hedley, R. W., K. K. Denton, and R. E. Weiss. 2017. Accounting for syntax in analyses of countersinging reveals hidden vocal dynamics in a songbird with a large repertoire. Animal Behaviour 131:2332 .

Hedwig, D., R. Mundry, M. M. Robbins, and C. Boesch. 2015. Contextual correlates of syntactic variation in mountain and western gorilla close-distance vocalizations: indications for lexical or phonological syntax? Animal Cognition 18:423-435.

Heimbauer, L. A., C. M. Conway, M. H. Christiansen, M. J. Beran, and M. J. Owren. 2018. Visual artificial grammar learning by rhesus macaques (Macaca mulatta): exploring the role of grammar complexity and sequence length. Animal Cognition 21:267-284.

Kanwal, J. S., S. Matsumura, K. Ohlemiller, and N. Suga. 1994. Analysis of acoustic elements and syntax in communication sounds emitted by mustached bats. Journal of the Acoustical Society of America 96:1229-1254.

Kershenbaum, A., A. Ilany, L. Blaustein, and E. Geffen. 2012. Syntactic structure and geographical dialects in the songs of male rock hyraxes. Proceedings of the Royal Society B 279:2974-2981.

Marler, P., and S. Peters. 1988. The role of song phonology and syntax in vocal learning preferences in the song sparrow, Melospiza melodia. Ethology 77:125-149.

Oliva, M. V., K. Kaiser, J. M. Robertson, and D. A. Gray. 2018. Call recognition and female choice in a treefrog with a multicomponent call. Ethology 124:331-337.
Ouattara, K., A. Lemasson, and K. Zuberbühler. 2009. Campbell's monkeys use affixation to alter call meaning. PLoS ONE 4:11.

Percy, D. M., E. A. Boyd, and M. S. Hoddle. 2008. Observations of acoustic signaling in three sharpshooters: Homalodisca vitripennis, Homalodisca liturata, and Graphocephala atropunctata (Hemiptera: Cicadellidae). Annals of the Entomological Society of America 101:253-259.

Percy, D. M., G. S. Taylor, and M. Kennedy. 2006. Psyllid communication: acoustic diversity, mate recognition and phylogenetic signal. Invertebrate Systematics 20:431-445.

Pinker, S. 1994. The language instinct. HarperCollins, New York.

Pinker, S., and R. Jackendoff. 2005. The faculty of language: what's special about it? Cognition 95:201-236.

Reichert, M. S., J. Finck, and B. Ronacher. 2017. Exploring the hidden landscape of female preferences for complex signals. Evolution 71:1009-1024.

Robinson, J. G. 1984. Syntactic structures in the vocalizations of wedgecapped capuchin monkeys, Cebus olivaceus. Behaviour 90:46-78.

Rodríguez, R. L., and R. B. Cocroft. 2006. Divergence in female duetting signals in the Enchenopa binotata species complex of treehoppers (Hemiptera: Membracidae). Ethology 112:1231-1238.

Rodríguez, R. L., C. Haen, R. B. Cocroft, and K. D. Fowler-Finn. 2012. Males adjust signaling effort based on female matepreference cues. Behavioral Ecology 23:1218-1225.

Rodríguez, R. L., K. Ramaswamy, and R. B. Cocroft. 2006. Evidence that female preferences have shaped male signal evolution in a clade of specialized plant-feeding insects. Proceedings of the Royal Society B 273:2585-2593.

Rodríguez, R. L., L. E. Sullivan, and R. B. Cocroft. 2004. Vibrational communication and reproductive isolation in the Enchenopa binotata species complex of treehoppers (Hemiptera: Membracidae). Evolution 58:571-578.

Schamberg, I., D. L. Cheney, Z. Clay, G. Hohmann, and R. M. Seyfarth. 2016. Call combinations, vocal exchanges and interparty movement in wild bonobos. Animal Behaviour 122:109-116.

Soma, M., and C. Mori. 2015. The songbird as a percussionist: syntactic rules for non-vocal sound and song production in Java sparrows. PLoS ONE 10:e0124876.

Speck, B, R. L. Rodriguez, S. Seidita, S. Belo, S. Johnson, C. Conley, and C. Desjonquères. 2020. Data from: Combinatorial signal processing in an insect, American Naturalist, Dryad Digital Repository, https://doi.org/10.5061/dryad.r4xgxd28v.

Suzuki, T. N., M. Griesser, and D. Wheatcroft. 2019. Syntactic rules in avian vocal sequences as a window into the evolution of compositionality. Animal Behaviour 151:267-274.

Wilczynski, W., S. A. Rand, and M. J. Ryan. 1999. Female preferences for temporal order of call components in the tungara frog: a Bayesian analysis. Animal Behaviour 58:841-851.

Wood, T. K. 1980. Divergence in the Enchenopa binotata say complex (Homoptera: membracidae) effected by host plant adaptation. Evolution 34:147.

1993. Speciation of the Enchenopa binotata complex (Insecta: Homoptera: Membracidae). Pages 299-317 in D. R. Lees and D. Edwards, eds. Evolutionary patterns and processes. Academic, New York.

Zuberbühler, K. 2019. Evolutionary roads to syntax. Animal Behaviour 151:259-265

Associate Editor: Rebecca J. Safran Editor: Russell Bonduriansky 